\title{
Clinical Study \\ Treatment of Dentine Hypersensitivity by Diode Laser: A Clinical Study
}

\author{
Romeo Umberto, Russo Claudia, Palaia Gaspare, \\ Tenore Gianluca, and Del Vecchio Alessandro \\ Department of Oral and Maxillofacial Sciences, Sapienza University of Rome, Via Caserta 6, 00161 Rome, Italy \\ Correspondence should be addressed to Palaia Gaspare, gaspare.palaia@uniroma1.it
}

Received 30 March 2012; Revised 5 May 2012; Accepted 6 May 2012

Academic Editor: S. Nammour

Copyright ( 92012 Romeo Umberto et al. This is an open access article distributed under the Creative Commons Attribution License, which permits unrestricted use, distribution, and reproduction in any medium, provided the original work is properly cited.

\begin{abstract}
Introduction. Dentine hypersensitivity (DH) is characterized by pain after stimuli that usually provoke no symptoms. This study compared the effectiveness of GaAlAs diode laser alone and with topical sodium fluoride gel (NaF). Materials and Methods. The study was conducted on 10 patients ( $8 \mathrm{~F} / 2 \mathrm{M}$, age 25-60) and 115 teeth with $\mathrm{DH}$ assessed by air and tactile stimuli measured by Numeric Rating Scale (NRS). Teeth were randomly divided into G1 (34 teeth) treated by 1.25\% NaF; G2 (33 teeth) lased at $0.5 \mathrm{~W}$ PW (T on $100 \mathrm{~m}$ and T off $100 \mathrm{~ms}$ ), fluence $62.2 \mathrm{~J} / \mathrm{cm}^{2}$ in defocused mode with a $320 \mu$ fiber. Each tooth received three $1^{\prime}$ applications; G3 (48 teeth) received NaF gel plus laser at same G2 parameters. NRS was checked at each control. Results. Significant pain reduction was showed. The NRS reduction percentages were calculated, and there was a concrete decrease of DH above all in G3 than G2 and G1. Conclusion. Diode laser is a useful device for DH treatment if used alone and mainly if used with NaF gel.
\end{abstract}

\section{Introduction}

Dentine hypersensitivity $(\mathrm{DH})$ is an abnormal response of the exposed vital dentine to thermal, chemical, or tactile stimuli. The prevalence of $\mathrm{DH}$ has been reported ranging from 4 to $57 \%$ in many studies in the literature, depending on the population samples studied $[1,2]$. In patients affected by periodontitis, $\mathrm{DH}$ prevalence was even higher ranging between 60 to $98 \%$ [3]. However, DH prevalence is likely to increase in next years since more adults keep their teeth into later life. This condition may affect patients at any age, and both genders are equally affected $[4,5]$.

Pain of dentinal origin is sharp, localized, and of short duration. Although different theories have been proposed for the mechanism involved in DH etiology, recent studies gave support to Brannstrom's hydrodynamic theory [6], according to this a stimulus applied to open tubules dentin increases the flow of dentinal tubular fluid, with mechanical deformation of the nerves located into the inner ends of the tubules or in the outer layers of the pulp [7]. Type A delta fibers are supposed to be responsible for dentinal sensitivity being probably activated by the hydrodynamic process [8].
The most common factors involved in DH are abrasion, caused by inadequate intensity tooth brushing; abfraction, caused by teeth flexion due to abnormal occlusal forces; parafunctions or occlusal disequilibrium; erosion, secondary to the presence of acids in the oral cavity, as in bulimia nervosa or gastroesophageal reflux; anatomic predisposition due to structural deficiency of the enamel-cement junction; cavity preparations in vital teeth that expose dentine or badly controlled dentinal acid conditioning [8-10].

Orchardson and Gillam showed that DH affects above all the vestibule-cervical area of teeth [4]. Cervical DH has probably a multifactorial etiology, and more than a cause is related to this painful manifestation. Therefore, several treatments must be associated to reduce DH to satisfactory levels. According to Garone-Filho [10] the abfraction, caused by occlusal overload, is the most common etiological factor related to $\mathrm{DH}$. So an occlusal adjustment should be always associated to the treatment of $\mathrm{DH}$.

Furthermore, according to Pashley [11], there are two types of dentinal permeability: intratubular, into the dentinal tubules, and intertubular, between the tubules in dentinal 
matrix. The sensitive dentine is permeable through its thickness; any treatment that reduces dentinal permeability must reduce dentinal sensitivity. The greatest dentine diffusion capacity allows the best interaction with the desensitizing agent. In fact, occlusion of the exposed dentinal tubules may decrease dentinal sensitivity level [9-14]. However, the DH sometimes persists despite of the effective sealing of the tubules, so indicating that further mechanisms are involved in nerves activation instead of or in addition to the hydrodynamic mechanism. Many authors suggested the hypothesis concerning the release of neuropeptides from the activated nervous terminations and, subsequently, the induction of a neurogenic inflammation. This hypothesis should signify that the symptoms of DH could become selfsustainable up to a certain point $[8,14]$.

Another great problem related to $\mathrm{DH}$ is its evaluation, since pain is a highly subjective sensation. Nevertheless, it is possible to classify the DH according to Matsumoto's criteria. In this classification, three degrees of $\mathrm{DH}$ are recognized: grade 1 mild discomfort/pain, grade 2 moderate pain, and grade 3 characterized by intense and unbearable pain [15].

Through literature examination emerges that there is no therapy that can always reduce pain at satisfactory levels, even with the combination of different protocols. According to Landry and Voyer [16], there is not an ideal desensitizing agent but any kind of treatment for DH should be effective from the first application and must satisfy these parameters established by Grossman since 1934 [17]: (1) not irritating pulp, nor causing pain, (2) easy application, (3) long-lasting effect, (4) not discoloring or staining teeth, (5) not irritating soft tissues or periodontal ligament, (6) low cost.

Every treatment, that reduces dentinal permeability, diminishes dentinal sensitivity. The occlusion of dentinal tubules leads to the reduction of dentinal permeability so decreasing the degree of $\mathrm{DH}[11]$. According to the hydrodynamic theory, the effectiveness of dentine desensitization agents is directly related to their capacity of promoting the sealing of the dentinal canaliculi [12].

Conventional therapies for $\mathrm{DH}$ are based on the local application of desensitizing agents, either professionally or at home. The most frequently used agents can be classified as protein precipitants [18], tubule-occluding agents $[19,20]$, tubule sealants [21]. The sodium fluoride gel (NaF), which belongs to the tubule-occluding agents family, is the most commonly used agent $[4,22-25]$. Its mechanism relies on the mechanical occlusion that is accomplished by precipitation of insoluble calcium fluoride crystals within the tubules without adhesion. For this reason, it cannot resist to the stresses of the oral environment and its action decreases with time $[4,23]$.

In the last fifteen years, the introduction of lasers gave further possibilities to DH therapy [22, 26-29]. Laser photobiomodulating action in dental pulp was reported by many authors as in Villa et al. [30], with histological studies of dental pulp of mice, after laser irradiation in teeth with exposed dentine. In this study, the authors registered a large quantity of tertiary dentine production in lased teeth, that caused the physiological obliteration of tubules, while the nonirradiated control showed intense inflammatory process that, in some

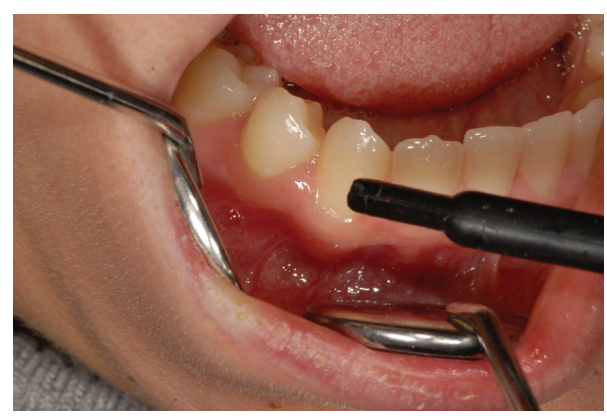

FIgURE 1: Air stimulus application.

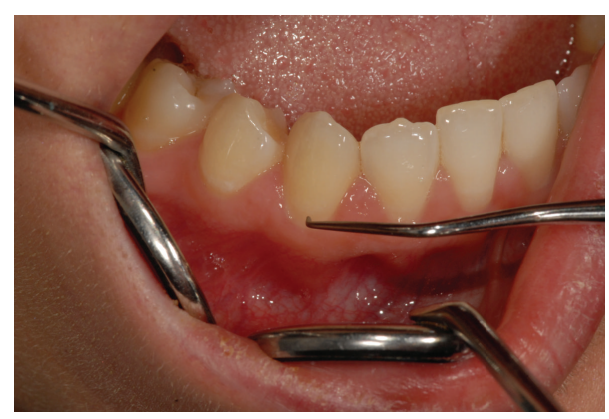

Figure 2: Tactile stimulus application.

cases, evolved into necrosis. Focusing on the role of laser in $\mathrm{DH}$ therapy, it is possible to show that its action is twofold. By one side, the low-level power lasers [14, 31], also called "soft lasers," act directly on nerve transmission, with a depolarization process that prevents the diffusion of pain to SNC; however, their effectiveness seems poorer in higher degrees of DH. By the other side, high-power lasers such as: diode $980 \mathrm{~nm}$ and $808 \mathrm{~nm}$, KTP $532 \mathrm{~nm}$, Nd: YAG $1064 \mathrm{~nm}$, $\mathrm{CO}_{2} 10600$ nm, Er, Cr: YSGG 2780 nm, and Er: YAG 2940 nm act on $\mathrm{DH}$ provoking a melting effect with crystallization of dentine inorganic component and the coagulation of fluids contained into the dentinal tubules. Among these "high power" devices, diode lasers are the most studied and the ones that gave the best results in several clinical protocols even in high-grade $\mathrm{DH}$ cases.

The aim of this study is to assess the efficacy of a diode GaAlAs laser alone and in combination with topical sodium fluoride gel $(\mathrm{NaF})$ in the treatment of $\mathrm{DH}$ in order to evaluate the possibilities of this device in the management of this painful condition.

\section{Materials and Methods}

The study was conducted on 10 patients ( 8 females and 2 males; aged from 25 to 60 years) and in a total of 115 teeth with DH assessed by mean of both air (Figure 1) and tactile (Figure 2) stimuli measured by the Numeric Rating Scale (NRS).

The inclusion criteria for patient enrollment were based on: the absence of local (e.g., cavities, fractures) and/or systemic pathologies, on the absence of contraindications to 


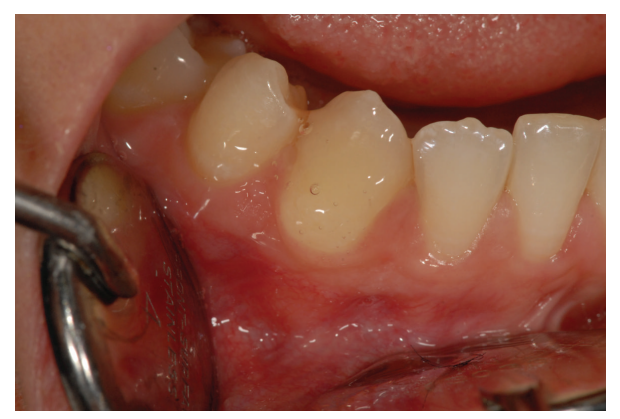

FIGURE 3: NaF gel application (Group 1).

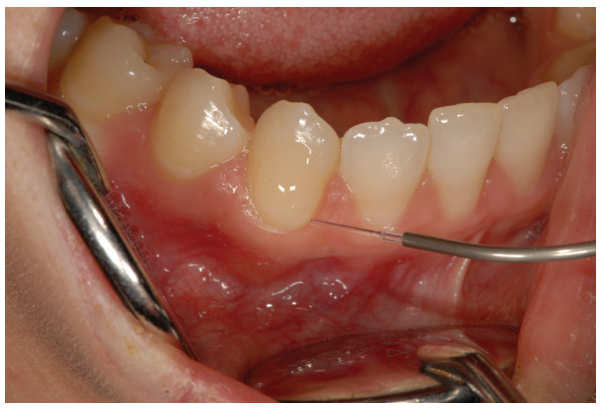

Figure 4: GaAlAs laser application (Group 2).

the proposed therapies (e.g., allergies to desensitizing agents) and on the presence of teeth with $\mathrm{DH}$ evaluated by pain response to both air and tactile stimuli that were registered by NRS scale (from 0 to 10 , where 0 meant the absence of pain and 10 represented an unbearable pain and discomfort felt by the patients in their life); at last no desensitizing therapy had to be previously performed, nor analgesic drugs had to be recently assumed.

Before any treatment, all the patients received a hygiene professional program with oral hygiene instructions and the teeth vitality of all sites was assessed.

For each patient, the sensitive sites were randomly divided into three groups:

(i) Group 1 (G1) (34 teeth) treated with 1.25\% NaF applied for 60 seconds on tooth surface (Figure 3);

(ii) Group 2 (G2) (33 teeth) lased by a GaAlAs laser (DoctorSmile, Lambda S.p.A., Brindole (Vi), Italy, $980 \mathrm{~nm}$ ) with these parameters: $0.5 \mathrm{~W}$ in PW (T on $100 \mathrm{~ms}$ and $\mathrm{T}$ off $100 \mathrm{~ms}$ ) and fluence of $62.2 \mathrm{~J} / \mathrm{cm}^{2}$ in no contact mode and using a fiber of 320-micron diameter. Each site received 3 applications of 1 minute each (Figure 4) once a week for three weeks;

(iii) Group 3 (G3) (48 teeth) treated using both NaF gel and diode laser at the same parameters of G2. The $\mathrm{NaF}$ gel was left on tooth surface for 60 seconds before the irradiation; in this way, the laser system could favor the permanence of desensitizer for a longer time than when it was used alone (Figure 5).

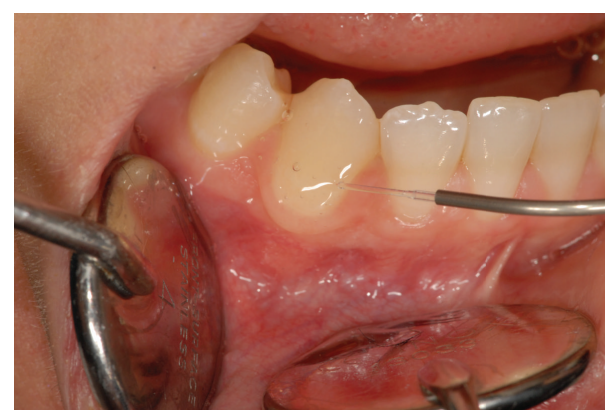

Figure 5: GaAlAs laser application + NaF gel application.

Patients' response to cold air blast was assessed by a short blast of 1-second duration at a distance of $0.5 \mathrm{~cm}$ for each tooth. Both air and tactile stimuli evaluations were performed before and after every treatment session, for a total of 3 treatment sessions at a distance of about one week each other.

The obtained results have been statistically analyzed through the Graphpad Prism 5.0 software.

\section{Results}

All the groups registered significant improvements of discomfort. A reduction of DH occurred during the treatment sessions, and the positive values were maintained after 1 month (Tables 1, 2, and 3).

Comparing the three regimens, a higher decrease of $\mathrm{DH}$ was registered in G3, followed by G2 and G1, respectively, whose results seem to be almost superimposable. The NRS reduction percentage was valued for each group between the first pretreatment and the third posttreatment session (Immediate-/-). The values were divided depending on the kind of stimulation. For the air stimulus, the reduction percentage was, respectively, 10.19\% (I) for G1; $22.35 \%$ (I) for G2; $25.04 \%$ (I) for G3. Furthermore, the tactile stimulus took down: $4.13 \%$ (I) for G1; 6.77\% (I) for G2; 9.96\% (I) for G3.

Regarding to the statistical analyses, the data relating to the probe test (Figure 6) were subjected to the KruskalWallis's test which demonstrated the reliability of the study $(P<0.0001)$. The comparative Dunn's test showed a statistically significant difference in G3 $(P<0.001)$, and in G1 $(P<0.01)$. In $\mathrm{G} 2$ the obtained improvement were lesser statistically significant $(P<0.1)$.

The results obtained with the cold blast (Figure 7) air were always analyzed through the Kruskal-Wallis's test which demonstrated the reliability of the study $(P<0.0001)$ and the comparative Dunn's test showed a statistically significant difference in each treated group $(P<0.001)$.

The improvement obtained in the samples of the probe test was not statistically significative $(P>0.05)$ instead of the samples of the cold blast air in which the improvements from the first treatment to the last one were superimposable. 
TABLE 1: Chart of NRS pretreatment, posttreatment, and at 1-month control values of the G1 (only NaF gel).

\begin{tabular}{|c|c|c|c|c|c|}
\hline $\begin{array}{l}\text { Preair } \\
\text { evaluation }\end{array}$ & $\begin{array}{c}\text { Postair } \\
\text { evaluation }\end{array}$ & $\begin{array}{c}\text { Air control } \\
1 \text { month }\end{array}$ & $\begin{array}{c}\text { Preprobe } \\
\text { evaluation }\end{array}$ & $\begin{array}{l}\text { Postprobe } \\
\text { evaluation }\end{array}$ & $\begin{array}{c}\text { Probe control } \\
1 \text { month }\end{array}$ \\
\hline 4 & 7 & 0 & 3 & 1 & 0 \\
\hline 5.5 & 0 & 0 & 6.5 & 0 & 0 \\
\hline 5.5 & 0 & 0 & 3 & 0 & 0 \\
\hline 10 & 2 & 0 & 6 & 0 & 0 \\
\hline 10 & 0 & 0 & 10 & 0 & 0 \\
\hline 5.5 & 0 & 0 & 5 & 1 & 0 \\
\hline 3 & 0 & 0 & 5 & 1 & 0 \\
\hline 3 & 0 & 0 & 3 & 0 & 0 \\
\hline 4 & 0 & 0 & 0 & 0 & 0 \\
\hline 3 & 0 & 1 & 0 & 0 & 0 \\
\hline 1 & 0 & 2 & 0 & 0 & 0 \\
\hline 1 & 0 & 0 & 0 & 0 & 0 \\
\hline 1 & 0 & 2 & 1 & 0 & 0 \\
\hline 2 & 0 & 0 & 0 & 0 & 0 \\
\hline 2 & 0 & 0 & 0 & 0 & 0 \\
\hline 2 & 0 & 0 & 0 & 0 & 0 \\
\hline 1 & 0 & 0 & 0 & 0 & 0 \\
\hline 0 & 0 & 2 & 6 & 0 & 0 \\
\hline 0 & 0 & 0 & 6 & 0 & 0 \\
\hline 7 & 1 & 0 & 7 & 0 & 0 \\
\hline 4 & 1 & 1 & 0 & 0 & 0 \\
\hline 1 & 0 & 0 & 0 & 0 & 0 \\
\hline 1 & 0 & 0 & 0 & 0 & 0 \\
\hline 1 & 0 & 0 & 0 & 0 & 0 \\
\hline 1 & 0 & 0 & 0 & 0 & 0 \\
\hline 0 & 0 & 0 & 2.5 & 0 & 0 \\
\hline 0 & 0 & 0 & 4 & 0 & 0 \\
\hline 2 & 0 & 0 & 0 & 0 & 0 \\
\hline 3 & 0 & 0 & 0 & 0 & 0 \\
\hline 10 & 0 & 0 & 0 & 0 & 0 \\
\hline 10 & 2 & 0 & 4.5 & 0 & 0 \\
\hline 5 & 0 & 0 & 0 & 0 & 0 \\
\hline 5 & 0 & 0 & 0 & 0 & 0 \\
\hline 5 & 0 & 0 & 0 & 0 & 0 \\
\hline
\end{tabular}

\section{Discussion}

Through literature examination, it is clarified that the ideal treatment for $\mathrm{DH}$ does not exist, even in case of combination of different protocols.

Conventional therapies for the treatment of DH comprehend the topical use of desensitizing agents, either professionally or at home such as protein precipitants [18], tubule-occluding agents $[19,20]$, tubule sealants $[21]$, and, recently, lasers [22, 26-29].

Several studies [32-34] describe a synergistic action of lasers in association with desensitizing agents. In fact, the laser system can favor the permanence of the desensitizer for longer time than when they are used alone. For this reason, if laser device is used in addition to a conventional desensitizing agent, the latter remains above the tooth surface for 60 seconds before the irradiation.

Focusing on the effectiveness of the sole diode laser, this was investigated by several authors. Matsumoto et al. [35] showed an $85 \%$ improvement in teeth treated with laser; Aun et al. [36] reported success in laser-irradiated teeth in 98\% of their cases; Yamaguchi et al. [37] noticed an effective improvement index of $60 \%$ in the group treated with laser compared to the $22.2 \%$ of the control nonlased group; Kumazaki et al. [38] showed an improvement of $69.2 \%$ in the group treated with laser compared to $20 \%$ in the placebo group. Gerschman et al. [39], in a double-blind study, found significant values in the laser-treated group. In fact, sensitivity to thermal stimuli was reduced by $67 \%$, whereas the placebo group had a reduction of $17 \%$, sensitivity to 
TABLE 2: Chart of NRS pretreatment, posttreatment, and at 1-month control values of the G2 (only Diode laser).

\begin{tabular}{|c|c|c|c|c|c|}
\hline $\begin{array}{l}\text { Preair } \\
\text { evaluation }\end{array}$ & $\begin{array}{c}\text { Postair } \\
\text { evaluation }\end{array}$ & $\begin{array}{c}\text { Air control } \\
1 \text { month }\end{array}$ & $\begin{array}{c}\text { Preprobe } \\
\text { evaluation }\end{array}$ & $\begin{array}{l}\text { Postprobe } \\
\text { evaluation }\end{array}$ & $\begin{array}{c}\text { Probe control } \\
1 \text { month }\end{array}$ \\
\hline 6 & 0 & 1 & 5 & 0 & 0 \\
\hline 2 & 0 & 0 & 0 & 0 & 0 \\
\hline 3 & 0 & 0 & 2.5 & 0 & 0 \\
\hline 4 & 0 & 0 & 1.5 & 1 & 0 \\
\hline 8 & 4 & 0 & 3 & 0 & 0 \\
\hline 8 & 4 & 0 & 3 & 0 & 0 \\
\hline 3 & 0 & 0 & 0 & 0 & 0 \\
\hline 1 & 0 & 0 & 0 & 0 & 0 \\
\hline 1 & 0 & 0 & 3.5 & 0 & 0 \\
\hline 4 & 3 & 1 & 0 & 0 & 0 \\
\hline 5 & 1 & 0 & 0 & 0 & 0 \\
\hline 4 & 0 & 1 & 0 & 0 & 0 \\
\hline 4 & 1 & 3 & 0 & 0 & 0 \\
\hline 2 & 0 & 0 & 0 & 0 & 0 \\
\hline 5 & 2 & 1 & 2 & 0 & 0 \\
\hline 2 & 2 & 2 & 0 & 1 & 2 \\
\hline 1 & 0 & 0 & 0 & 0 & 0 \\
\hline 2 & 0 & 0 & 0 & 0 & 0 \\
\hline 5 & 0 & 0 & 0 & 0 & 0 \\
\hline 7 & 0 & 0 & 3 & 0 & 0 \\
\hline 1 & 0 & 0 & 0 & 0 & 0 \\
\hline 1 & 0 & 0 & 0 & 0 & 0 \\
\hline 1 & 0 & 0 & 0 & 0 & 0 \\
\hline 3 & 0 & 0 & 3 & 0 & 0 \\
\hline 3 & 0 & 2 & 3 & 0 & 0 \\
\hline 2 & 0 & 0 & 0 & 0 & 0 \\
\hline 6.5 & 0 & 0 & 0 & 0 & 0 \\
\hline 8 & 3.5 & 0 & 0 & 0 & 0 \\
\hline 5 & 3 & 0 & 0 & 0 & 0 \\
\hline 5 & 0 & 0 & 0 & 0 & 0 \\
\hline 5 & 2 & 0 & 0 & 0 & 0 \\
\hline 5 & 0 & 0 & 0 & 0 & 0 \\
\hline 5 & 3 & 0 & 0 & 0 & 0 \\
\hline
\end{tabular}

tactile stimuli was reduced by $65 \%$, while the placebo group showed a reduction of $21 \%$. Another study carried out by Brugnera et al. [40] showed the immediate analgesic effect using a diode laser.

In this study, significant improvements in pain and discomfort were always registered after the session treatments (I) even if in no case the percentages of pain reduction arrived to the high values registered in the literature.

As a first laser showed the best immediate results alone and in combination with gel, since the percentages of pain reduction in G2 and G3 were more than twice than G1 values. In our sample, the best results were obtained by the association of laser and $\mathrm{NaF}$ gel therapy (G3). This group registered the highest I reduction, in particular for air blast stimulation. It is probable that the better performance of combined treatment was due to the higher $\mathrm{NaF}$ gel adhesion to the dentinal tubules when combined with laser energy.
In the laser group, G2, the immediate pain reduction was very high especially at air stimulation $(22.35 \% \mathrm{I})$; in the same group, the improvement at tactile stimulation was poorer after the treatment $(6.77 \% \mathrm{I})$. The lower reduction values were registered in the sole gel group, G1, by both stimulations, in the immediate period.

Even in consideration of the short sample analyzed, it is possible to speculate that the laser-induced superficial melting permits to keep longer the tubules occlusion by NaF gel emphasizing the reduction of $\mathrm{DH}$-related pain.

\section{Conclusion}

According to these results, the GaAlAs laser showed a very high capability to improve immediately the DH-related pain, both alone and even better in combination with NaF gel. On the other hand, the sole gel results, even if positive, cannot 
TABLE 3: Chart of NRS pretreatment, posttreatment, and at 1-month control values of the G3 (NaF gel + Diode laser).

\begin{tabular}{|c|c|c|c|c|c|}
\hline $\begin{array}{l}\text { Preair } \\
\text { evaluation }\end{array}$ & $\begin{array}{c}\text { Postair } \\
\text { evaluation }\end{array}$ & $\begin{array}{c}\text { Air control } \\
1 \text { month }\end{array}$ & $\begin{array}{c}\text { Preprobe } \\
\text { evaluation }\end{array}$ & $\begin{array}{l}\text { Postprobe } \\
\text { evaluation }\end{array}$ & $\begin{array}{c}\text { Probe control } \\
1 \text { month }\end{array}$ \\
\hline 7 & 0 & 0 & 4 & 0 & 0 \\
\hline 7 & 0 & 4 & 1 & 0 & 0 \\
\hline 8 & 8 & 8 & 9 & 7 & 4 \\
\hline 2 & 0 & 0 & 7 & 0 & 0 \\
\hline 2 & 0 & 0 & 0 & 0 & 0 \\
\hline 8 & 7 & 5.5 & 9 & 0 & 0 \\
\hline 5 & 0 & 3 & 5 & 0 & 0 \\
\hline 9 & 4 & 6 & 9 & 0 & 0 \\
\hline 7 & 0 & 7 & 7 & 3 & 0 \\
\hline 4 & 5 & 3 & 8 & 0 & 2 \\
\hline 4 & 2 & 3 & 0 & 0 & 0 \\
\hline 7 & 0 & 0 & 9 & 0 & 0 \\
\hline 7 & 0 & 0 & 7 & 0 & 0 \\
\hline 10 & 1 & 3 & 10 & 2 & 0 \\
\hline 6 & 0 & 0 & 3 & 0 & 0 \\
\hline 8 & 0 & 0 & 8 & 0 & 0 \\
\hline 10 & 10 & 0 & 10 & 1 & 0 \\
\hline 5 & 1 & 0 & 3.5 & 0 & 0 \\
\hline 3 & 0 & 0 & 1.5 & 0 & 0 \\
\hline 3 & 0 & 0 & 3 & 0 & 0 \\
\hline 9 & 0 & 0 & 9 & 0 & 0 \\
\hline 10 & 5 & 0 & 1.5 & 0 & 0 \\
\hline 10 & 7 & 0 & 3 & 0 & 0 \\
\hline 5 & 1 & 2 & 0 & 0 & 0 \\
\hline 6 & 2 & 0 & 0 & 0 & 0 \\
\hline 10 & 0.5 & 0.5 & 2 & 0 & 0 \\
\hline 10 & 1 & 0 & 2 & 0 & 0 \\
\hline 10 & 1 & 0 & 2 & 0 & 0 \\
\hline 2 & 0 & 0 & 0 & 0 & 0 \\
\hline 3 & 2 & 0 & 2 & 0 & 0 \\
\hline 3 & 2 & 0 & 4 & 1 & 0 \\
\hline 4 & 0 & 0 & 4 & 1 & 0 \\
\hline 2 & 0 & 0 & 0.5 & 0 & 0 \\
\hline 5 & 0 & 0 & 0 & 0 & 0 \\
\hline 9 & 0 & 2 & 0 & 0 & 0 \\
\hline 8 & 1 & 0 & 8 & 0 & 0 \\
\hline 1 & 0 & 0 & 0 & 0 & 0 \\
\hline 3 & 0 & 0 & 0 & 0 & 0 \\
\hline 3 & 0 & 0 & 0 & 0 & 0 \\
\hline 1 & 0 & 0 & 1 & 0 & 0 \\
\hline 10 & 0 & 0 & 0 & 0 & 0 \\
\hline 10 & 0 & 0 & 0 & 0 & 0 \\
\hline 0 & 0 & 0 & 2.5 & 0 & 0 \\
\hline 5 & 0 & 0 & 0 & 0 & 0 \\
\hline 5 & 4 & 0 & 0 & 0 & 0 \\
\hline 10 & 4 & 0 & 0 & 0 & 0 \\
\hline 8 & 3 & 0 & 0 & 0 & 0 \\
\hline 5 & 0 & 0 & 0 & 0 & 0 \\
\hline
\end{tabular}




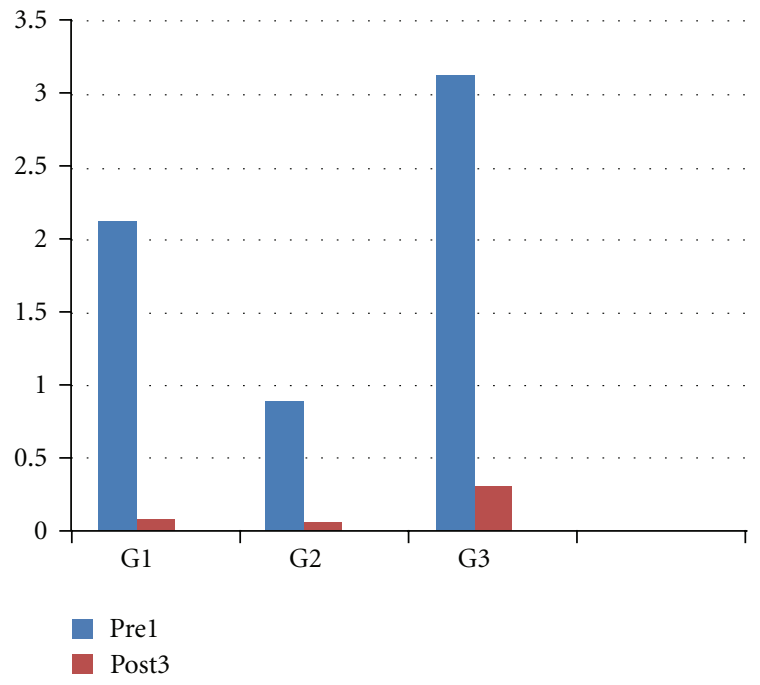

FIGURE 6: Illustrative representation of the improvements to the tactile stimuli from the first treatment to the third one.

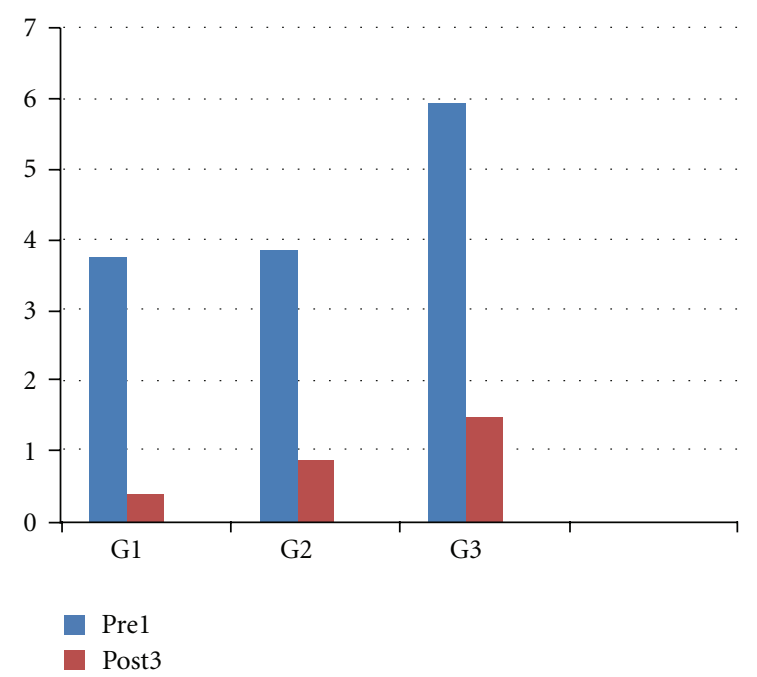

FIGURE 7: Illustrative representation of the improvement to the air stimuli from the first treatment to the third one.

equalize the performances of laser in the immediate. These results have to be confirmed by greater samples of patients and by longer follow-up periods (e.g., 3 and 6 months) to confirm or not the long-lasting action of the combined laser and gel therapy.

\section{References}

[1] C. R. Irwin and P. McCusker, "Prevalence of dentine hypersensitivity in a general dental population," Journal of the Irish Dental Association, vol. 43, no. 1, pp. 7-9, 1997.

[2] J. S. Rees and M. Addy, "A cross-sectional study of dentine hypersensitivity," Journal of Clinical Periodontology, vol. 29, no. 11, pp. 997-1003, 2002.

[3] M. B. Chabanski, D. G. Gillam, J. S. Bulman, and H. N. Newman, "The prevalence, distribution and severity of cervical dentine sensitivity (CDS) in a population of patients referred to a specialist periodontology department," Journal of Clinical Periodontology, vol. 23, pp. 989-992, 1996.

[4] R. Orchardson and D. G. Gillam, "Managing dentin hypersensitivity," Journal of the American Dental Association, vol. 137, no. 7, pp. 990-998, 2006.

[5] S. D. Ipci, G. Cakar, B. Kuru, and S. Yilmaz, "Clinical evaluation of lasers and sodium fluoride gel in the treatment of dentine hypersensitivity," Photomedicine and Laser Surgery, vol. 27, no. 1, pp. 85-91, 2009.

[6] B. Matthews and N. Vongsavan, "Interactions between neural and hydrodynamic mechanisms in dentine and pulp," Archives of Oral Biology, vol. 39, no. 1, pp. S87-S95, 1994.

[7] M. Brannström, "A hydrodynamic mechanism in the transmission of pain-producing stimuli through dentine," in Sensory Mechanism in Dentine, D. J. Anderson, Ed., pp. 73-79, Pergamon, Oxford, UK, 1963.

[8] T. C. C. G. P. Ladalardo, A. Pinheiro, R. A. D. C. Campos et al., "Laser therapy in the treatment of dentine hypersensitivity," Brazilian Dental Journal, vol. 15, no. 2, pp. 144-150, 2004.

[9] M. Brännstrom, "Etiology of dentin hypersensitivity," Proceedings of the Finnish Dental Society, vol. 88, pp. 7-13, 1992.

[10] W. Garone-Filho, "Lesões cervicais e hipersensibilidade dentinária," in Atualização na clínica odontológica: a prática na clínica geral, F. F. Todescan and M. A. Bottino, Eds., pp. 3573, Artes Médicas, São Paulo, Brazil, 1996.

[11] D. H. Pashley, "Dentin permeability and dentin sensitivity," Proceedings of the Finnish Dental Society, vol. 88, pp. 31-37, 1992.

[12] T. Y. Ling and D. G. Gillam, "The effectiveness of desensitizing agents for the treatment of cervical dentine sensitivity (CDS)—a review," The Journal of the Western Society of Periodontology/Periodontal abstracts, vol. 44, no. 1, pp. 5-12, 1996.

[13] J. F. Siqueira, "Hipersensibilidade dentinária: visão atual dos mecanismos envolvidos e medidas erapêuticas," Revista SulBrasileira de Odontologia, vol. 11, no. 6, pp. 55-58, 1994.

[14] M. Oda, A. Matos, and E. Uberti, "A morfologia da dentina tratada com substâncias dessensibilizantes: avaliação através de microscopia eletrônica de varredura," Revista de Odontologia da Universidade de São Paulo, vol. 13, pp. 337-342, 1999.

[15] K. Matsumoto et al., "Study on the treatment of hypersensitive dentine by Ga-Al-As laser diode," Japanese Journal of Conservative Dentistry, vol. 28, pp. 766-771, 1985.

[16] R. G. Landry and R Voyer, "Le traitement de l' hypersensibilité dentinaire: une étude rétrospective et comparative de deux approches thérapeutiques," Journal of the Canadian Dental Association, vol. 56, pp. 1035-1041, 1990.

[17] L. E. Grossman, "The treatment of hypersensitive dentine," The Journal of the American Dental Association, vol. 22, pp. 592-602, 1935.

[18] L. P. Gangarosa, "Current strategies for dentist-applied treatment in the management of hypersensitive dentine," Archives of Oral Biology, vol. 39, no. 1, pp. S101-S106, 1994.

[19] D. G. Kerns, M. J. Scheidt, D. H. Pashley, J. A. Horner, S. L. Strong, and T. E. Van Dyke, "Dentinal tubule occlusion and root hypersensitivity," Journal of Periodontology, vol. 62, no. 7, pp. 421-428, 1991.

[20] R. Ikemura, "Studies on new treatment agents for dentin hypersensitivity," Japanese Journal of Conservative Dentistry, vol. 36, pp. 1686-1698, 1993.

[21] T. G. Wichgers and R. L. Emert, "Dentin hypersensitivity," General Dentistry, vol. 44, no. 3, pp. 225-232, 1996.

[22] A. Moritz, U. Schoop, K. Goharkhay et al., "Long-term effects of $\mathrm{CO}_{2}$ laser irradiation on treatment of hypersensitive dental 
necks: results of an in vivo study," Journal of Clinical Laser Medicine and Surgery, vol. 16, no. 4, pp. 211-215, 1998.

[23] P. J. Hsu, J. H. Chen, F. H. Chuang, and R. T. Roan, "The combined occluding effects of fluoride-containing dentin desensitizer and Nd-YAG laser irradiation on human dentinal tubules: an in vitro study," Kaohsiung Journal of Medical Sciences, vol. 22, no. 1, pp. 24-29, 2006.

[24] S. A. M. Corona, T. N. Do Nascimento, A. B. E. Catirse, R. F. Z. Lizarelli, W. Dinelli, and R. G. Palma-Dibb, "Clinical evaluation of low-level laser therapy and fluoride varnish for treating cervical dentinal hypersensitivity," Journal of Oral Rehabilitation, vol. 30, no. 12, pp. 1183-1189, 2003.

[25] N. G. Kumar and D. S. Mehta, "Short-term assessment of the Nd:YAG laser with and without sodium flouride varnish in the treatment of dentin hypersensitivity-a clinical and scanning electron microscopy study," Journal of Periodontology, vol. 76, no. 7, pp. 1140-1147, 2005.

[26] A. Moritz, N. Gutknecht, U. Schoop et al., "The advantage of $\mathrm{CO}_{2}$-treated dental necks, in comparison with a standard method: results of an in vivo study," Journal of Clinical Laser Medicine and Surgery, vol. 14, no. 1, pp. 27-32, 1996.

[27] C. Zhang, K. Matsumoto, Y. Kimura, T. Harashima, F. H. Takeda, and $\mathrm{H}$. Zhou, "Effects of $\mathrm{CO}_{2}$ laser in treatment of cervical dentinal hypersensitivity," Journal of Endodontics, vol. 24, no. 9, pp. 595-597, 1998.

[28] F. Schwarz, N. Arweiler, T. Georg, and E. Reich, "Desensitizing effects of an Er:YAG laser on hypersensitive dentine: a controlled, prospective clinical study," Journal of Clinical Periodontology, vol. 29, no. 3, pp. 211-215, 2002.

[29] H. Watanabe, K. Kataoka, H. Iwami, T. Shinoki, Y. Okagami, and I. Ishikawa, "In vitro and in vivo studies on application of erbium:YAG laser for dentine hypersensitivity," International Congress Series, vol. 1248, pp. 455-457, 2003.

[30] R. G. Villa, A. Brugnera, and C. E. Aun, "Estudo histológico da atuação do raio laser He:Ne na neoformação dentinária em polpa de ratos," V Oncris SBPq, p. 101, 1988.

[31] A. Sicilia, S. Cuesta-Frechoso, A. Suárez, J. Angulo, A. Pordomingo, and P. De Juan, "Immediate efficacy of diode laser application in the treatment of dentine hypersensitivity in periodontal maintenance patients: a randomized clinical trial," Journal of Clinical Periodontology, vol. 36, no. 8, pp. 650-660, 2009.

[32] N. G. Kumar and D. S. Mehta, "Short-term assessment of the Nd:YAG laser with and without sodium flouride varnish in the treatment of dentin hypersensitivity-a clinical and scanning electron microscopy study," Journal of Periodontology, vol. 76, no. 7, pp. 1140-1147, 2005.

[33] W. H. Lan, H. C. Liu, and C. P. Lin, "The combined occluding effect of sodium fluoride varnish and Nd:YAG laser irradiation on human dentinal tubules," Journal of Endodontics, vol. 25, no. 6, pp. 424-426, 1999.

[34] S. Pesevska, M. Nakova, K. Ivanovski et al., "Dentinal hypersensitivity following scaling and root planing: comparison of low-level laser and topical fluoride treatment," Lasers in Medical Science, vol. 25, no. 5, pp. 647-650, 2010.

[35] K. Matsumoto, H. Tomonari, and H. Wakabayashi, "Study on the treatment of hypersensitive dentine by laser," Journal of Conservative Dentistry, vol. 28, pp. 1366-1371, 1985.

[36] C. A. Aun, A. Brugnera-Júnior, and R. G. Villa, "Raio laserHipersensibilidade dentinária," Revista da APCD, vol. 43, no. 2, pp. 65-68, 1989.

[37] M. Yamaguchi, M. Ito, T. Miwata et al., "Clinical study on the treatment of hypersensitive dentin by GaAlAs laser diode using the double blind test," Aichi Gakuin Daigaku Shigakkai shi, vol. 28, no. 2, pp. 703-707, 1990.

[38] M. Kumazaki, K. Zennyu, M. Inoue, and B. Fujii, "Clinical evaluation of GaAlAs-semiconductor laser in the treatment of hypersensitive dentin," Japanese Journal of Conservative Dentistry, vol. 33, pp. 911-918, 1990.

[39] J. A. Gerschman, J. Ruben, and J. Gebart-Eaglemont, "Low level laser therapy for dentinal tooth hypersensitivity," Australian Dental Journal, vol. 39, no. 6, pp. 353-357, 1994.

[40] A. Brugnera, F. Zanin, and A. Pinheiro, "LLLT in treating dentinary hypersensibility: a histologic study and clinical application," in Proceedings of the 2nd International Conference on Near-Field Optical Analysis: Photodynamic Therapy \& Photobiology Effects (NOA '02), pp. 23-31, Houston, Tex, USA, June 2001. 


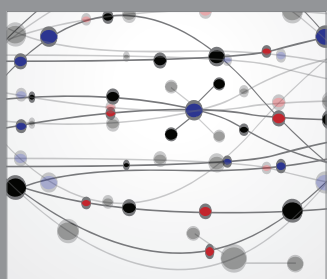

The Scientific World Journal
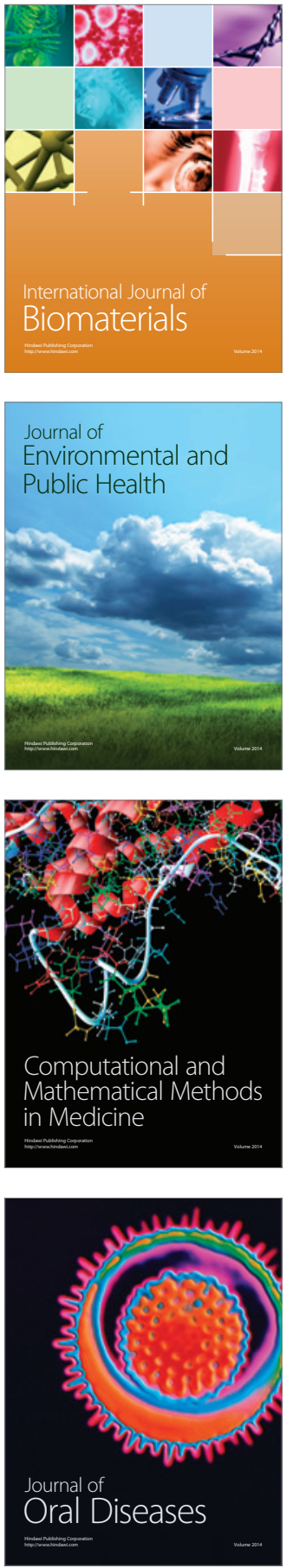
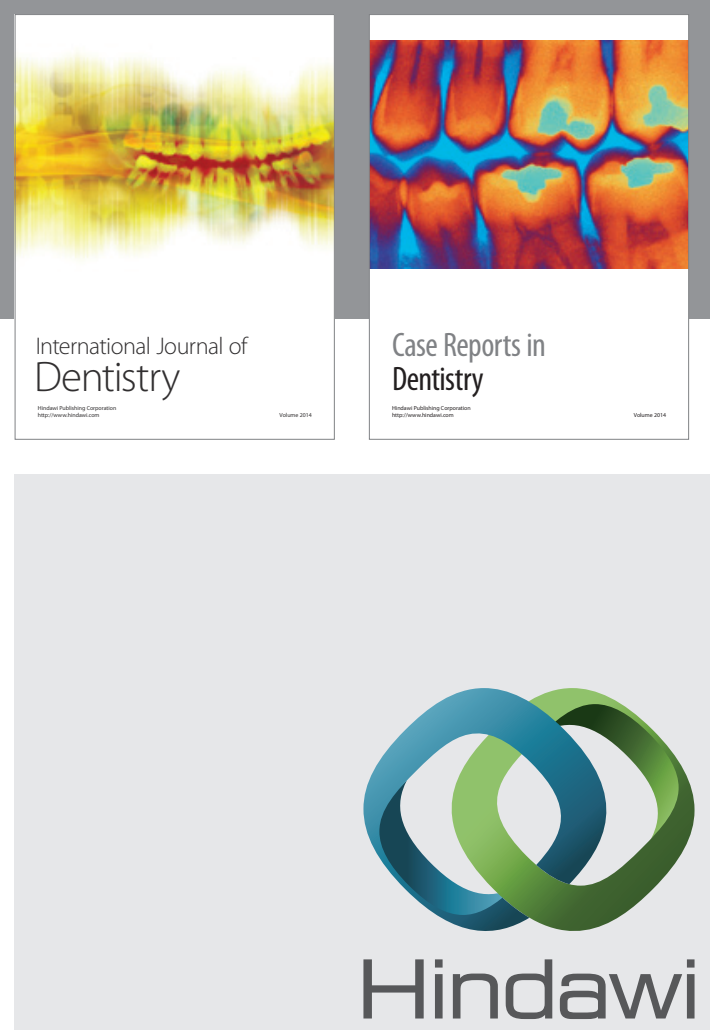

Submit your manuscripts at

http://www.hindawi.com
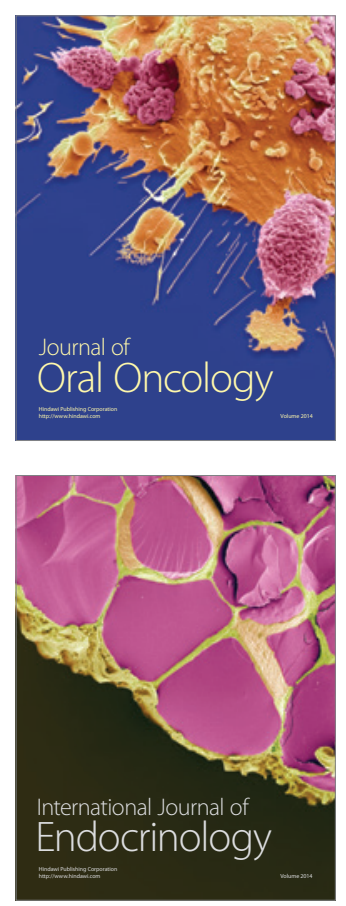
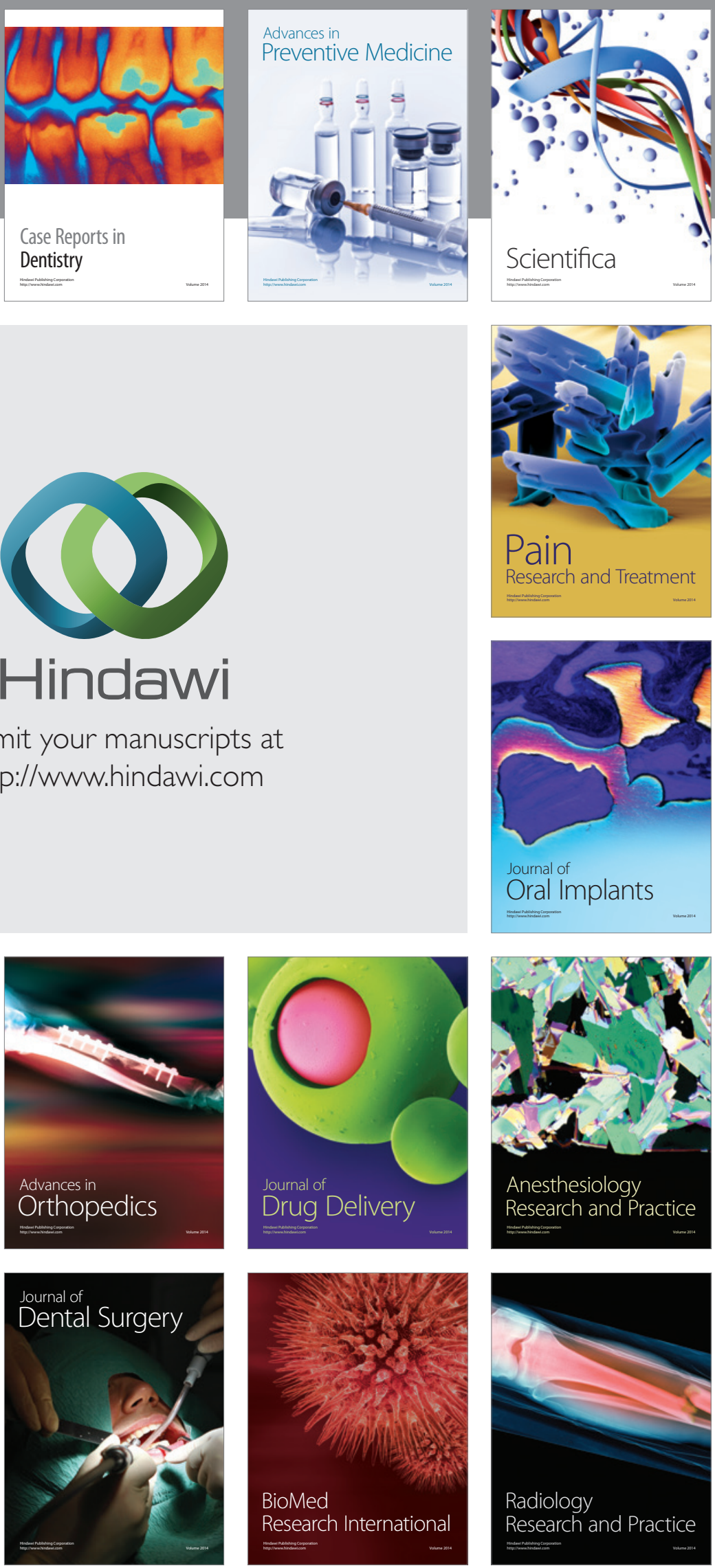